Article

\title{
Analysis of Ocean Tide Loading in Differential InSAR Measurements
}

\author{
Wei Peng, Qijie Wang * and Yunmeng Cao \\ School of Geosciences and Info-Physics, Central South University, Changsha 410083, Hunan, China; \\ pengweicsu@163.com (W.P.); ymcmrs@csu.edu.cn (Y.C.) \\ * Correspondence: qjwang@csu.edu.cn; Tel.: +86-138-0842-5350
}

Academic Editors: Xiaofeng Li and Prasad S. Thenkabail

Received: 19 August 2016; Accepted: 18 January 2017; Published: 24 January 2017

\begin{abstract}
Ocean tide loading (OTL) causes crustal displacements in coastal regions, and the relative variation of these ground displacements may reach several centimeters across differential interferometric synthetic aperture radar (DInSAR) interferograms. However, orbit errors seriously affect the analysis of long-wavelength crustal deformation signals such as the OTL effect because of their similar signatures in DInSAR interferograms. To correct the orbit errors, we used a linear surface model to model the relative displacements of the Global Positioning System (GPS) precise point positioning (PPP) in the line of sight (LOS) direction as a priori parameter of the long-wavelength crustal deformation signals. After correcting the orbit errors, an ocean tide model was applied to correct the OTL effect in the DInSAR interferograms. The proposed approach was verified with the DInSAR interferograms from the Los Angeles basin. The experimental results confirm that the real orbit errors can be modeled by the bilinear ramp function under the constraint of the priori parameter. Moreover, after removing the orbit errors, the OTL effect, which is dominant in the long-wavelength crustal deformation signals, can be revealed, and then be effectively eliminated by the FES2004 tide model.
\end{abstract}

Keywords: ocean tide loading; DInSAR; precise point positioning; ocean tide model

\section{Introduction}

Ocean tide loading (OTL), which is an elastic response of the solid Earth to the oceanic mass redistribution, can cause near-shore crustal deformation of several centimeters [1]. The interferometric synthetic aperture radar (InSAR) technique is able to measure such small changes of Earth's surface [2-5]. However, OTL correction by an ocean tide model is not usually taken into consideration in differential InSAR (DInSAR) measurements. DiCaprio and Simons [6] discussed the importance of OTL correction in DInSAR based on an empirical ocean tide model, and they showed the superiority of an ocean tide model in correcting the OTL effect in DInSAR. Some studies acknowledged the OTL effect in DInSAR measurements as a potential error source and tried to use empirical models to correct it [7-9]. However, whether or not an ocean tide model can be used for spatial analysis is still unclear, and needs to be verified with real data. It is for this reason that both a method to reveal the OTL effect in DInSAR measurements and further illustration of the validity of ocean tide model correction with real DInSAR measurements are needed.

The orbit errors, the OTL effect and crustal long-wavelength tectonic deformation have similar spatial characteristics [10]. Therefore, it is very difficult to distinguish the OTL effect in DInSAR measurements from the other similar signals and a priori parameter of the OTL effect from external data is needed. GPS have been demonstrated to be able to analyze the temporal characteristics of the OTL effect [11]. Specifically, the amplitudes and phase lags of each constituent of the OTL displacement in a certain place can be estimated with GPS precise point positioning (PPP) [12-15]. In addition to 
the temporal feature, the OTL effect in sub-daily PPP solutions has a spatial feature approximating to the bilinear ramp function. In this study, we first removed the PPP solutions with obvious gross errors. The remaining available PPP solutions are then converted to the line of sight (LOS) direction, and their relative displacements are fitted to the linear surface model by a robust regression model. The linear surface model, a priori parameter, was assumed to represent the real spatial long-wavelength crustal deformation signals, including the OTL effect. The orbit errors can be estimated from the DInSAR interferograms by taking the priori parameter as the constraint condition. After removing the orbit errors from the DInSAR interferograms, the long-wavelength crustal deformation signals in the DInSAR interferograms, including the OTL effect, were revealed. If the OTL effect is dominant in the long-wavelength crustal deformations, the DInSAR interferograms after orbit error correction can be used to further analyze the validity of the ocean tide model correction.

\section{Methodology}

Before analyzing the crustal deformations caused by the OTL effect in DInSAR interferograms, the orbit errors should be accurately removed under the constraint of the relative displacements of the PPP solutions in the LOS direction. The ocean tide model is then applied to correct the OTL effect in the DInSAR interferograms.

Three main steps are involved in the analysis of the OTL effect in DInSAR interferograms:

1. Obtain the phase-unwrapped DInSAR interferograms before the baseline re-estimation.

2. Estimate the orbit errors in the DInSAR interferograms. Firstly, calculate the 2-hour static PPP solutions using the data from GPS reference stations in the SAR image range and areas nearby. Each PPP solution covers the epoch of one hour before and after the SAR imaging time. These PPP solutions are regarded as the crustal deformations, including the OTL effect, at the each SAR imaging time. The relative displacements of each PPP solution are also calculated, and are then converted to the LOS direction and fitted to the linear surface model using the robust regression model to create the priori parameter. Finally, subtract the corresponding values of the priori parameter from each pixel in the DInSAR interferograms, and fit them by the bilinear ramp function in estimating the orbit errors.

3. Remove the orbit errors from the original DInSAR interferograms to reveal the long-wavelength crustal deformation signals, and then use an ocean tide model to eliminate the OTL effect.

The flow chart is shown in Figure 1.

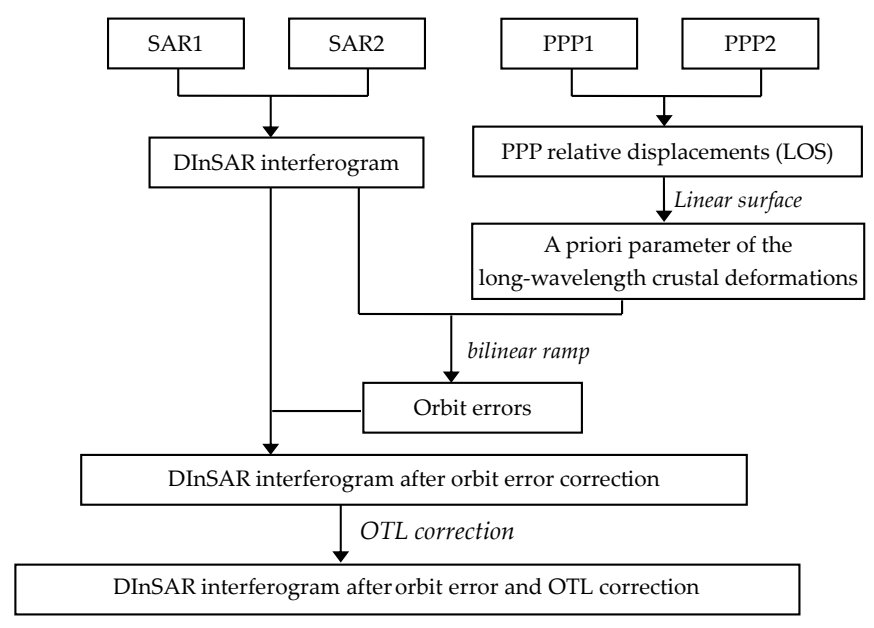

Figure 1. Flow chart for analyzing the orbit errors and ocean tide loading (OTL) effect in differential interferometric synthetic aperture radar (DInSAR) measurements. 
Orbit errors in DInSAR measurements are usually described as a quasi-quadratic surface [16], so they are usually modeled by the bilinear ramp function. In order to ensure that the OTL effect is not falsely removed as "orbit errors" [10], we used the priori parameter of the spatial long-wavelength crustal deformation signals in estimating the orbit errors.

$\Delta N, \Delta E$, and $\Delta H$ are assumed to be the three components of the real surface deformation in the directions of north, east, and up, respectively. The PPP relative displacements could be converted to the LOS direction as shown in the following formula [17].

$$
d \Delta r_{P P P}=\Delta H_{P P P} \cdot \cos \theta+\left(\Delta E_{P P P} \cdot \cos \Phi+\Delta N_{P P P} \cdot \sin \Phi\right) \cdot \sin \theta
$$

where $\triangle N_{P P P}, \triangle E_{P P P}$, and $\triangle H_{P P P}$ are the three components of the real surface deformation measured by PPP, $\theta$ is the radar incidence angle and $\Phi$ is the angle between the flight direction of the SAR satellite and the north direction. $d \triangle r_{P P P}$ was fitted to the linear surface model by the robust regression model to model the priori parameter [18].

$$
d \triangle r_{P P P}(x, y)=a_{0}+a x+b y
$$

where $(x, y)$ is the location of the pixel in the DInSAR interferograms corresponding to the GPS reference station. We solved equation coefficients $a_{0}, a$, and $b$ to calculate the value of each points on the priori parameter $d_{\text {Constraints }}$.

We subtracted the priori parameter of the spatial long-wavelength crustal deformation signals from the DInSAR interferograms, and the results were fitted by the bilinear ramp function by the robust regression model.

$$
d_{\text {DInSAR }}-d_{\text {Constraints }}=a_{0}^{*}+a^{*} x+b^{*} y+c^{*} x y
$$

We solved equation coefficients $a_{0}^{*}, a^{*}, b^{*}$, and $c^{*}$ to calculate the orbit errors $d_{\text {orbit }}$.

$d_{\text {orbit }}$ was removed from the original DInSAR interferograms by:

$$
d=d_{\text {DInSAR }}-d_{\text {orbit }}
$$

where $d$ is the DInSAR interferograms without orbit errors. If the long-wavelength tectonic deformations are much smaller than the OTL effect, the OTL effect is dominant in the residual long-wavelength signals. Therefore, the residual long-wavelength signals were used to analyze the importance of the ocean tide model correction applied to the process of DInSAR interferograms.

\section{Data Set and Processing}

\subsection{DInSAR Interferograms}

The ENVISAT satellite usually revisits a place at a similar local time, because of the polar orbit geometry. However, the OTL effect has a cycle different from that of the SAR acquisition time, which leads to variation in the OTL effect measured by SAR.

When analyzing the OTL effect in DInSAR interferograms, we need to model the GPS data as the priori parameter of the spatial long-wavelength crustal deformation signals. In the Los Angeles basin, there are more than 50 GPS reference stations covered by the footprint of interferograms. We used a data set of 22 ASAR ENVISAT SLC images from the Los Angeles region to analyze the OTL effect in the DInSAR interferograms. These data cover the period from 19 January 2008 to 25 September 2010, and the SAR acquisition time is about 18:01:00 UTC. The phase-unwrapped DInSAR interferograms were obtained by the GAMMA software (GAMMA_SOFTWARE-2009121) [19].

\subsection{PPP Solution}

In total, 55 GPS stations inside the SAR image and areas nearby were selected. The GPS data were processed using Bernese GPS Software V5.0 [20] in the PPP mode of the Bernese Processing 
Engine (BPE) module, with an ambiguity-float solution. The GPS RINEX data are obtained from the Scripps Orbit and Permanent Array Center (SOPAC) [21]. The International GNSS Service (IGS) precise ephemeris, the precise satellite clock, and the Earth rotation parameters were used. The correction file of the antenna phase center used IGS PHAS_COD.I08, and the tropospheric mapping function used the Niell Mapping Function (NMF). The solid Earth body tides were modeled by IERS2010. The OTL was not modeled in the GPS data processing.

\subsection{Ocean Tide Loading Correction}

We used the Some Programs for Ocean-Tide Loading (SPOTL) program to calculate the OTL displacements [22]. This software calculates the OTL displacements with ocean tide models. Many different global ocean tide models have been used for correcting the OTL effect, such as CSR4.0, NAO99b, FES2004, EOT11a, GOT00.2 and TPXO6.2. Among them, the FES2004 ocean tide model is a commonly used global ocean tide model in the Los Angeles basin [23]. Therefore, in this study the FES2004 ocean tide model was chosen to calculate the OTL displacements comprising the eight main constituents of the OTL (semi-diurnal tide: $\mathrm{M}_{2}, \mathrm{~S}_{2}, \mathrm{~N}_{2}, \mathrm{~K}_{2}$, diurnal tide: $\mathrm{K}_{1}, \mathrm{O}_{1}, \mathrm{P}_{1}, \mathrm{Q}_{1}$ ).

The three components of OTL displacements in the north, east, and up directions can be calculated using the SPOTL program. To apply the OTL displacements to the DInSAR interferograms, they were first converted to the LOS direction, and then their relative variations at each particular time were calculated.

\section{Analysis of the OTL Effect in DInSAR Interferograms}

DInSAR technology is concerned with temporal comparisons of the displacements at the pixel basis by repeat passes of the satellite. Meanwhile, we are also concerned with spatial comparisons across the footprint of each SAR image. We made a preliminary analysis of the spatial comparisons of two extreme points using the OTL displacements calculated by the SPOTL program. We selected $P_{n}^{1}$ (close to the coastline) and $P_{n}^{2}$ (far from the coastline) in the range of the $n$th SAR image and calculated their relative displacements in the LOS direction $\left(P_{n}^{1}-P_{n}^{2}\right)$ using the OTL displacements (Figure 2).
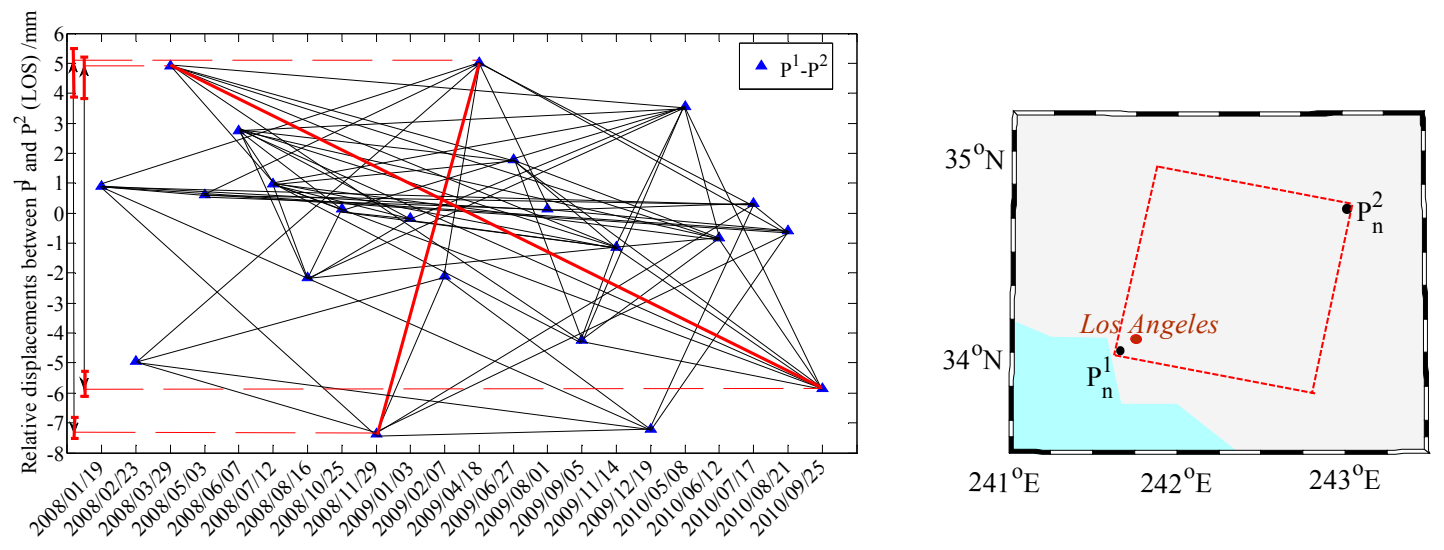

Figure 2. Variation of the relative displacements caused by the OTL effect between the near point $\left(P_{n}^{1}\right)$ and the far point $\left(P_{n}^{2}\right)$ in the line of sight (LOS) direction; The variations of the relative displacements $P_{n}^{1}-P_{n}^{2}$ in two selected DInSAR interferograms (D0912 and D0322) are marked in red, the uncertainties are the changes of the OTL displacements from 17:00:00 to 19:00:00 UTC.

By analyzing the relative variations caused by the OTL effect of the two extreme points in Figure 2, we computed a maximum range for the OTL effect in our study area. The absolute values of the relative variations of $P^{1}$ and $P^{2}$ in the two selected DInSAR interferograms, D0912 and D0322, are $1.08 \mathrm{~cm}$ and $1.24 \mathrm{~cm}$ (red line in Figure 2). D0912 was generated from the 9th SAR 
image (date: 29 November 2008) and the 12th SAR image (date: 18 April 2009). D0322 was generated from the 3rd SAR image (date: 29 March 2008) and the 22nd SAR image (date: 25 September 2010).

The PPP solutions were used to represent the real spatial long-wavelength crustal deformation signals, including the OTL effect, at the SAR imaging time. Therefore, we used the 2-hour GPS data segments, from 17:00:00 to 19:00:00 UTC, to calculate the PPP solutions. The middle time of the GPS data segments matches the SAR imaging time of 18:01:00 UTC. The uncertainties are shown in Figure 2, which indicate the changes of the OTL displacements from 17:00:00 to 19:00:00 UTC.

The relative displacements of PPP solutions were calculated and converted to the LOS direction, and then were modeled to the linear surface model to obtain the priori parameter of the spatial long-wavelength crustal deformation signals corresponding to pixels of the DInSAR interferograms. The relative displacements of PPP and the priori parameters $d_{\text {Constraints }}^{\text {D0912 }} d_{\text {Constraints }}^{D 0322}$ are shown in Figures $3 \mathrm{a}$ and $4 \mathrm{a}$, respectively. Meanwhile, the relative variations of the OTL displacements of the FES2004 tide model were calculated (Figures $3 b$ and $4 b$ ), and compared with the priori parameter.

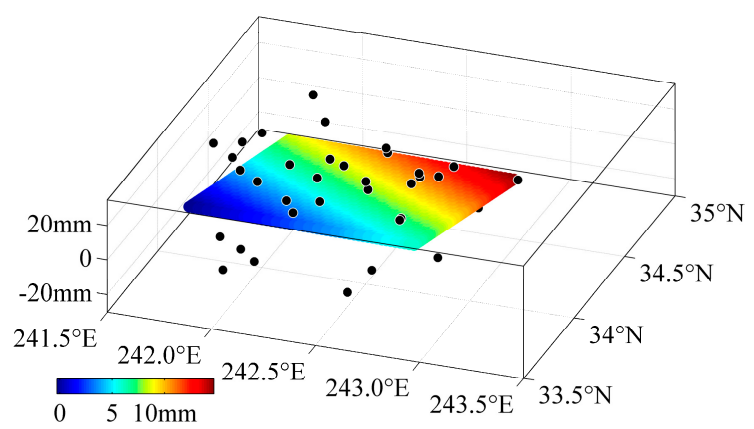

(a)

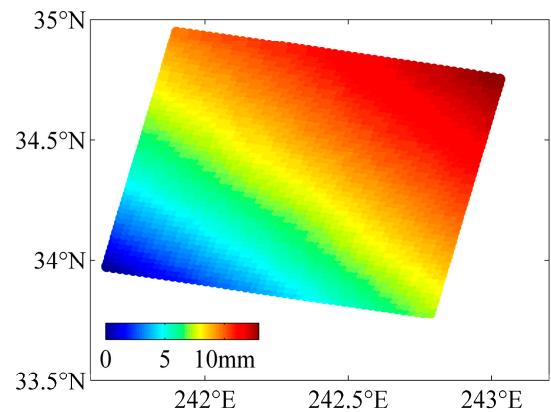

(b)

Figure 3. (a) The relative displacements of the precise point positioning (PPP) between 29 November 2008 18:01:00 and 18 April 2009 18:01:00, and the priori parameter of the spatial long-wavelength crustal deformation signals for estimating the orbit errors. (b) The relative variations of the OTL displacements of the FES2004 tide model over the same time period.

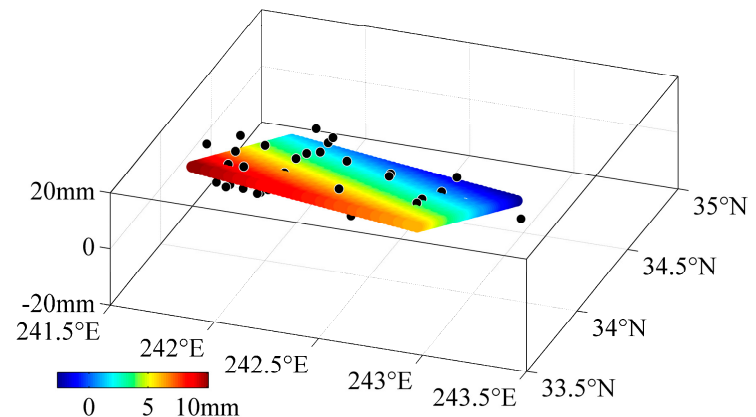

(a)

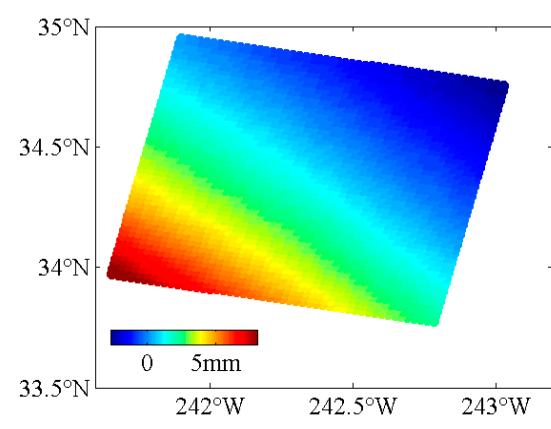

(b)

Figure 4. (a) The relative displacements of the PPP between 29 March 2008 18:01:00 and 25 September 2010 18:01:00, and the priori parameter of the spatial long-wavelength crustal deformation signals for estimating the orbit errors. (b) The relative variations of the OTL displacements of the FES2004 tide model over the same time period.

The root-mean-square (RMS) values of the differences between the priori parameter and the relative variations of the OTL displacements of the FES2004 tide model were also calculated (Table 1). Clearly, the OTL effect is dominant in the priori parameter of the long-wavelength crustal deformation signals in the two selected DInSAR interferograms. 
Table 1. Root-mean-square (RMS) of the differences between a priori parameter and the relative variations of the OTL displacements of FES2004 tide model.

\begin{tabular}{cc}
\hline & RMS/mm \\
\hline A priori parameter $d_{\text {Constraints }}^{\text {D012 }}$ and OTL displacements & 0.9 \\
A priori parameter $d_{\text {Constraints }}^{\text {D0322 }}$ and OTL displacements & 2.3 \\
\hline
\end{tabular}

The selected DInSAR interferograms show an obvious trend surface from $P^{1}$ to $P^{2}$ in the DInSAR interferograms (Figure 5).

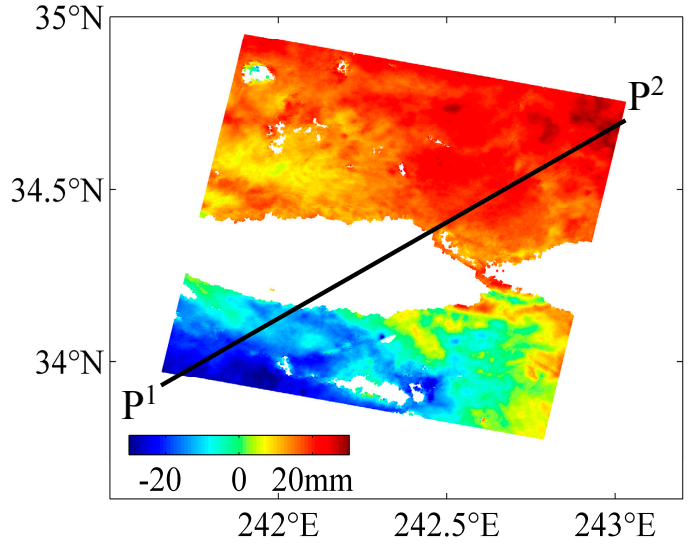

(a)

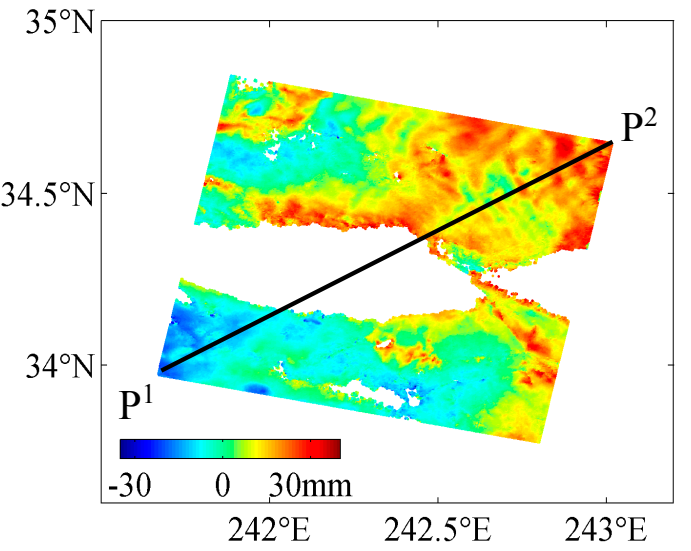

(b)

Figure 5. Two selected DInSAR interferograms D0912 (a) and D0322 (b).

In order to separate the orbit errors from the OTL signals, we accurately estimated the orbit errors under the constraint of the priori parameters $d_{\text {Constraints }}^{\mathrm{D} 0912}$ and $d_{\text {Constraints }}^{\mathrm{D} 0322}$. There is a mountain in the middle of the interferograms, and we marked this region as having a poor coherence. Therefore, we set the pixels values in the marked region as "NaN", which were ignored in modeling.

The estimated orbit errors were removed from the DInSAR interferograms D0912 and D0322 (Figure 5) by Fomula (4). After this, the trend surface from $P^{1}$ to $P^{2}$ in the DInSAR interferograms D0912 and D0322 was significantly weakened (Figure 6). However, the DInSAR interferograms D0912 and D0322 after orbit error correction still show trend variations of the long-wavelength signals are more than $1 \mathrm{~cm}$ across the interferograms, which may be caused by the OTL effect.

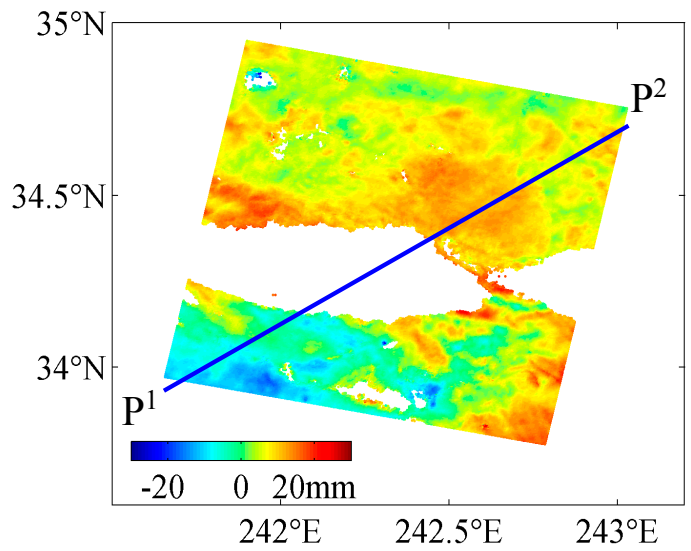

(a)

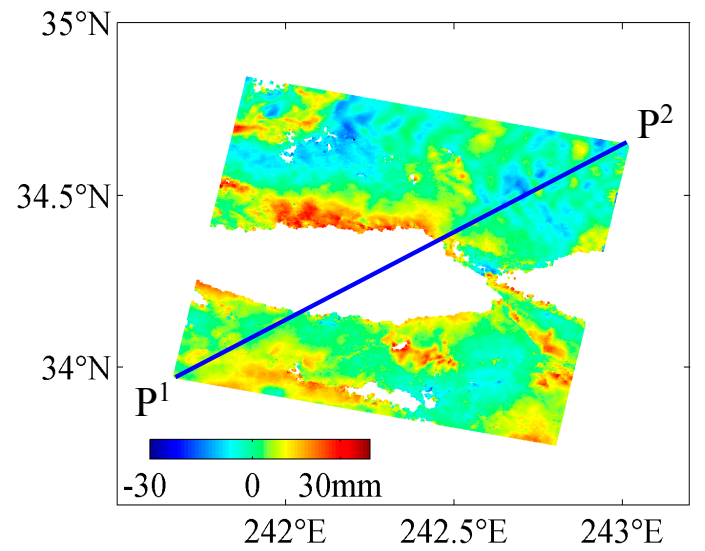

(b)

Figure 6. DInSAR interferograms D0912 (a) and D0322 (b) after orbit error corrections. 
To test the hypothesis that the residual trend variations from $P^{1}$ to $P^{2}$ (Figure 6) are caused by the OTL effect, we applied the OTL displacements of the FES2004 tide model to the interferograms. The results show that the residual long-wavelength signals are almost eliminated (Figure 7). This suggests that the residual long-wavelength signals are caused by the OTL effect, which can be effectively corrected by the OTL correction model.

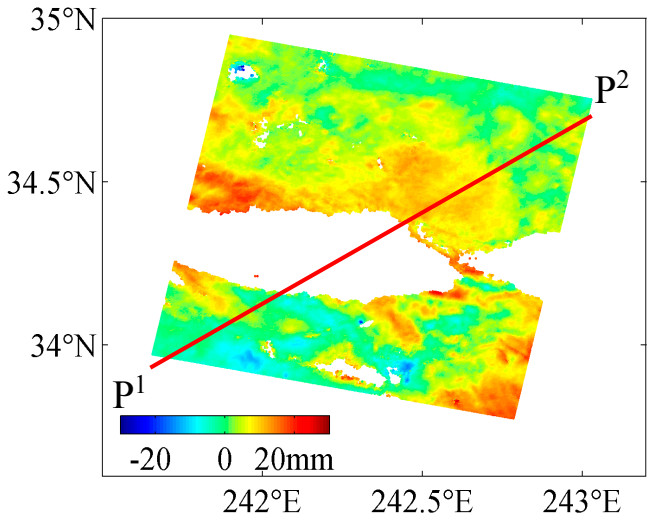

(a)

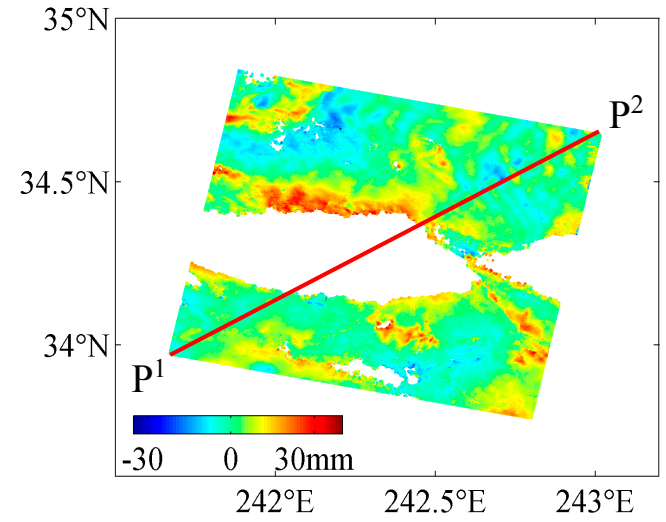

(b)

Figure 7. DInSAR interferogram D0912 (a) and D0322 (b) after the orbit error and ocean tide model correction.

To illustrate the effectiveness of the FES2004 tide model for correcting the OTL effect in DInSAR interferograms D0912 and D0322, all pixels from $P^{1}$ to $P^{2}$ were selected. These pixels have the largest range of OTL effect in the interferograms.

The pixel values from point $P^{1}$ to $P^{2}$ were fitted to lines, the variations in the line slopes in Figures 8 and 9 can reflect the actual effect of the orbit errors and the OTL effect in DInSAR interferograms D0912 and D0322. The effectiveness of the FES2004 tide model in correcting the OTL effect is shown in Table 2.

Table 2. Variations of the line slopes of pixel values from point $P^{1}$ to $P^{2}$ in DInSAR interferograms D0912 and D0322.

\begin{tabular}{ccc}
\hline Pixel Values & Linear Slope Variations in D0912 & Linear Slope Variations in D0322 \\
\hline Original observations & 0.1558 & 0.1216 \\
After orbit error correction & 0.0404 & -0.0379 \\
After orbit error and tide model correction & 0.0028 & -0.0028 \\
\hline
\end{tabular}

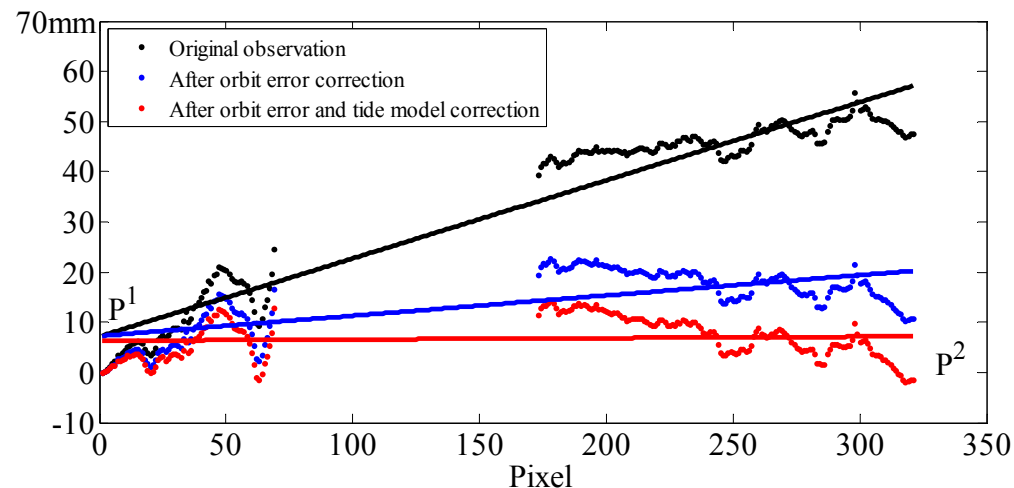

Figure 8. Change of pixel values from point $P^{1}$ to $P^{2}$ in DInSAR interferogram D0912. 


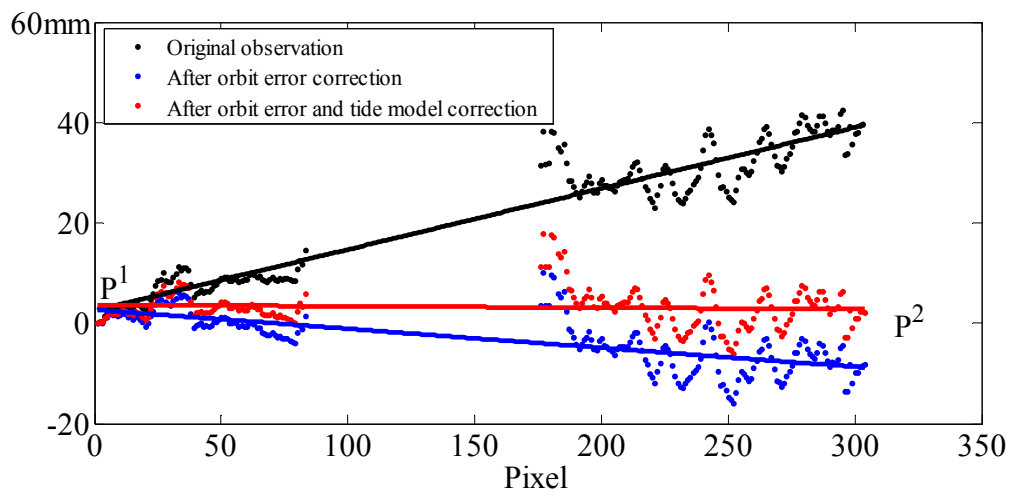

Figure 9. Change of pixel values from point $P^{1}$ to $P^{2}$ in DInSAR interferogram $D 0322$.

The line slopes of the observations after the orbit errors and tide model correction are 0.0028 , -0.0028 (red lines in Figures 8 and 9), which are close to zero. These results indicate that the ocean tide model can effectively correct the OTL effect in DInSAR interferograms.

We further analyzed the magnitude of the orbit errors and OTL effect by comparing the variations of the line slopes of the original observations, the pixel values after orbit error correction and the pixel values after orbit error and OTL effect correction (Figures 8 and 9). It was found that the OTL effect is about $33 \%$ of the orbit errors in D0912, and $22 \%$ of the orbit errors in D0322, which suggests that the OTL effect was incorrectly taken as orbit errors when the bilinear fitting was used to correct the "orbit errors" in DInSAR interferograms.

\section{Conclusions}

To estimate the orbit errors, we used the relative displacements of the GPS PPP to create a priori parameter of the spatial long-wavelength crustal deformation signals. An ocean tide model was then applied to correcting the OTL effect in DInSAR interferograms. The case study of the Los Angeles region showed that the OTL effect can be revealed in DInSAR interferograms after removing the orbit errors, and the FES2004 tide model can effectively model the OTL effect in real data. Furthermore, we quantitatively analyzed the OTL and orbit errors in the DInSAR interferograms. It was found that the OTL effect comprised up to $33 \%$ of the orbit errors, which indicates that the OTL effect can be a major source of the long-wavelength signals in DInSAR interferograms of near-shore areas.

Acknowledgments: This work was supported by the National Natural Science Foundation of China (grant Nos. 41404013, U1531128) and the Hunan Provincial Innovation Foundation for Postgraduate. The GPS data were provided by SOPAC and processed by Bernese GPS Software V5.0; the InSAR data were provided by ESA and processed by GAMMA software. The SPOTL program was used to produce the ocean tide loading correction.

Author Contributions: Wei Peng and Qijie Wang conceived and designed the experiments; Wei Peng and Yunmeng Cao performed the experiments; Wei Peng and Qijie Wang analyzed the data; Wei Peng wrote the paper.

Conflicts of Interest: The founding sponsors had no role in the design of the study; in the collection, analysis, or interpretation of the data; in the writing of the manuscript; and in the decision to publish the results.

\section{References}

1. Pagiatakis, S.D. The response of a realistic Earth to ocean tide loading. Geophys. J. Int. 1990, 103, 541-560. [CrossRef]

2. Massonnet, D.; Feigl, K.L. Radar interferometry and its application to changes in the earth's surface. Rev. Geophys. 1998, 36, 441-500. [CrossRef]

3. Xu, B.; Li, Z.; Feng, G.; Zhang, Z.; Wang, Q.; Hu, J.; Chen, X. Continent-Wide 2-D co-seismic deformation of the $2015 \mathrm{Mw} 8.3$ Illapel, Chile earthquake derived from Sentinel-1A data: Correction of azimuth co-registration error. Remote Sens. 2016, 8, 376. [CrossRef] 
4. Feng, G.; Li, Z.; Shan, X.; Zhang, L.; Zhang, G.; Zhu, J. Geodetic model of the 2015 April 25 Mw 7.8 Gorkha Nepal earthquake and Mw 7.3 aftershock estimated from InSAR and GPS data. Geophys. J. Int. 2015, 203, 896-900. [CrossRef]

5. Li, Z.; Zhao, R.; Hu, J.; Wen, L.; Feng, G.; Zhang, Z.; Wang, Q. InSAR analysis of surface deformation over permafrost to estimate active layer thickness based on one-dimensional heat transfer model of soils. Sci. Rep. 2015, 5, 15542. [CrossRef] [PubMed]

6. DiCaprio, C.J.; Simons, M. Importance of ocean tidal load corrections for differential InSAR. Geophys. Res. Lett. 2008, 35. [CrossRef]

7. Jolivet, R.; Agram, P.S.; Lin, N.Y.; Simons, M.; Doin, M.P.; Peltzer, G.; Li, Z. Improving InSAR geodesy using global atmospheric models. J. Geophys. Res. Solid Earth 2014, 119, 2324-2341. [CrossRef]

8. Lin, Y.N.; Jolivet, R.; Simons, M.; Agram, P.S.; Martens, H.R.; Li, Z.; Lodi, S.H. High interseismic coupling in the eastern Makran (Pakistan) subduction zone. Earth Planet. Sci. Lett. 2015, 420, 116-126. [CrossRef]

9. Tong, X.; Sandwell, D.T.; Smith-Konter, B. High-resolution interseismic velocity data along the San Andreas fault from GPS and InSAR. Can. J. Earth Sci. 2013, 118, 369-389. [CrossRef]

10. Bähr, H.; Hanssen, R.F. Reliable estimation of orbit errors in spaceborne SAR interferometry. J. Geodesy 2012, 86, 1147-1164. [CrossRef]

11. Thomas, I.D.; King, M.A.; Clarke, P.J. A comparison of GPS, VLBI and model estimates of ocean tide loading displacements. J. Geod. 2007, 81, 359-368. [CrossRef]

12. Allinson, C.R.; Clarke, P.J.; Edwards, S.J.; King, M.A.; Baker, T.F.; Cruddace, P.R. Stability of direct GPS estimates of ocean tide loading. Geophys. Res. Lett. 2004, 31. [CrossRef]

13. Yuan, L.G.; Ding, X.L.; Zhong, P.; Chen, W.; Huang, D.F. Estimates of ocean tide loading displacements and its impact on position time series in Hong Kong using a dense continuous GPS network. J. Geod. 2009, 83, 999-1015. [CrossRef]

14. Penna, N.T.; King, M.A.; Stewart, M.P. GPS height time series: Short-period origins of spurious long-period signals. J. Geophys. Res. Solid Earth 2007, 112, 1074-1086. [CrossRef]

15. Penna, N.T.; Clarke, P.J.; Bos, M.S.; Baker, T.F. Ocean tide loading displacements in western Europe: 1. validation of kinematic GPS estimates. J. Geophys. Res. Solid Earth 2015, 120. [CrossRef]

16. Pritchard, M.E.; Simons, M.; Rosen, P.A.; Hensley, S.; Webb, F.H. Co-seismic slip from the 1995 July $30 \mathrm{Mw}=8.1$ Antofagasta, Chile, earthquake as constrained by InSAR and GPS observations. Geophys. J. Int. 2002, 150, 362-376. [CrossRef]

17. Yang, Z.F.; Li, Z.W.; Zhu, J.J.; Hu, J.; Wang, Y.J.; Chen, G.L. InSAR-based model parameter estimation of probability integral method and its application for predicting mining-induced horizontal and vertical displacements. IEEE Trans. Geosci. Remote Sens. 2016, 54, 4818-4832. [CrossRef]

18. Holland, P.W.; Welsch, R.E. Robust regression using iteratively reweighted least-squares. Commun. Stat. Theory 1977, 6, 813-827. [CrossRef]

19. GAMMA Remote Sensing. Available online: http://www.gamma-rs.ch/gamma.html (accessed on 23 January 2017).

20. Bernese GNSS Software. Available online: http:/ /www.bernese.unibe.ch (accessed on 23 January 2017).

21. RINEX data of the Scripps Orbit and Permanent Array Center (SOPAC). Available online: ftp://garner.ucsd. edu/pub/rinex/ (accessed on 23 January 2017).

22. Agnew, D.C. SPOTL: Some Programs for Ocean-Tide Loading; Scripps Institution of Oceanography: La Jolla, CA, USA, 2012.

23. Lyard, F.; Lefevre, F.; Letellier, T.; Francis, O. Modelling the global ocean tides: Modern insights from FES2004. Ocean Dyn. 2006, 56, 394-415. [CrossRef]

(C) 2017 by the authors; licensee MDPI, Basel, Switzerland. This article is an open access article distributed under the terms and conditions of the Creative Commons Attribution (CC BY) license (http:/ / creativecommons.org/licenses/by/4.0/). 